\title{
The Effects of Tissue Regenerative Status on Hormesis in Dogs Irradiated during Their Lifespan
}

\author{
Aleksey N. Shoutko*, Ludmila P. Ekimova \\ Laboratory for Improvement of the Radiation Treatment Methods, Russian Research Center for Radiology and Surgical \\ Technologies, Saint-Petersburg, Russia \\ Email: *shoutko@inbox.ru
}

How to cite this paper: Shoutko, A.N. and Ekimova, L.P. (2017) The Effects of Tissue Regenerative Status on Hormesis in Dogs Irradiated during Their Lifespan. Open Journal of Biophysics, 7, 101-115. https://doi.org/10.4236/ojbiphy.2017.73009

Received: May 7, 2017

Accepted: July 2, 2017

Published: July 5, 2017

Copyright @ 2017 by authors and Scientific Research Publishing Inc. This work is licensed under the Creative Commons Attribution International License (CC BY 4.0).

http://creativecommons.org/licenses/by/4.0/

(c) † Open Access

\begin{abstract}
The goal of this study was to evaluate the influence of natural variation in the regenerative status of dog tissues on the signs of hormesis, which are evident after total body exposure to low daily doses of external gamma radiation throughout the lifespan. Ninety beagle dogs of both sexes were irradiated with cobalt 60 at $0.003 \mathrm{~Gy} /$ day commencing 1 year after birth to death. Control (n = 169) and irradiated animals underwent whole-life clinical observation and autopsy, and were then retrospectively divided into two subgroups with (W) or without benign tumors or tumors of unknown nature (WO) that were clinically recorded on single days throughout the lifespan. Radiation hormesis was only detected in subgroup WO, which had life span (LS) of 10.7 years in the absence of radiation. The radiogenic prolongation of life to 11.8 years in the WO subgroup ( $\mathrm{p}<0.05$ ) was similar to that in the W control and irradiated $W$ subgroups (11.8 and 11.5 years, respectively). The number of solid malignancies found upon autopsy of the control WO subgroup was less (39.5\%) than that evident in the control W subgroup (60\%). Compared to the irradiated W subgroup, irradiation of the WO subgroup was accompanied by a slight increase (1.14-fold) in the number of solid malignancies evident at autopsy and in the clinical signs of tissue atrophy and body weight loss (2.4-fold and 2.4-fold, respectively), but was accompanied by strong reductions in the extent of anemia and hemoblastoses ( $>10$-fold for both). The data exclude the notion that radiation is associated with healing, but suggest that certain pathologies (e.g., hemoblastoses) may be substituted with other less dangerous somatic diseases in weaker animals only.
\end{abstract}

\section{Keywords}

Hormesis, Chronic Irradiation, Dogs, Survival, Neoplasms, Reparation/Regeneration, Hemopoiesis 


\section{Introduction}

Studies on high-level natural background radiation, occupational exposure, and life in radon-containing environments have suggested that low-dose radiation has a hormetic effect (a biphasic dose-response with an optimum health index of about $0.000014 \mathrm{~Gy} /$ day). Earlier studies considered mortality from cancer, overall growth, life span (LS), and tissue regeneration capacity in this context [1] [2]. Recently, radiation hormesis has been considered a form of useful cancer therapy when total-body irradiation (TBI) is delivered to a cumulative dose of $1.5 \mathrm{~Gy}$ at about $0.1 \mathrm{~Gy} /$ day [3]. Many studies have attributed hormesis to potentiation of the immune system [1]-[8]. Any reported potentiation/stimulation conflicts with the tenets of the linear no-threshold (LNT) model, which emphasizes the harmful biological effects of radiation. Fliedner et al. [9] calculated that irradiation at 0.000014 and $0.1 \mathrm{~Gy} /$ day caused every cell in the body to stochastically receive either 0.05 of an event of average energy deposition (a hit)/day or more than 360 such events/day. It is difficult to explain the supposed immunopotentiation afforded by such a difference $\left(\approx 10^{4}\right.$-fold $)$ in the principal molecular parameter of injury.

Nevertheless, some members of an organization, entitled Scientists for Accurate Radiation Information, have requested the US National Research Council of the National Academy of Sciences to reject the LNT model in favor of a model embracing radiation hormesis in other words: "direct stimulation or overcompensation stimulation of anticancer immunity by low doses of radiation" [2] [5]. A recent radical statement, "the LNT [model] needs to be discarded and afforded the same credibility as Lysenkoism," [10] has triggered scientific confrontation.

Such confrontation would be less radical if hormesis was not caused by radiation-mediated stimulation, but rather, by radiation injury. Such a possibility has recently been rendered plausible by reports on changes in trophic and morphogenic properties upon renewal of rapidly proliferating tissues (both normal and malignant) attributable to the actions of special subsets of circulating hemopoietic stem and progenitor cells from the bone marrow (BM) and thymus, which enhanced the proliferation in tissues of other histotypes [11]-[17]. These data confirmed that the hemopoietic system exhibited a trophic (feeding) function, posing challenges to the assumptions of many models based on previously accepted notions of cellular immune defense. For example, if feeding is important, it is easy to explain why myelosuppression is beneficial during cancer treatment [18]. The novel idea also explains why the instantaneous rates of death from cancer decline, although the instantaneous rates of mortality from non- malignant and infectious diseases increase during age-dependent immune system involution [19] [20]. In addition, dogs exhibiting clinical signs of tissue hyperproliferation (either benign or of unknown nature) live longer, and are more radioresistant, because their $\mathrm{BM}$ constitutes a more potent proliferative resource [21].

Enhancement of cancer patient survival after short-term TBI or subtotal body 
irradiation (sTBI), delivered at cumulative doses of 11 and 1.9 Gy [12] [22] [23] [24], is a typical initial (positive) example of a biphasic hormetic reaction. Such doses are inadequate to directly control tumor growth, being 3 - 30-fold lower than the minimal doses used in conventional local radiation therapy [25] [26]. Nevertheless, both TBI and sTBI indirectly retard cancer progression by reducing the numbers of circulating feeding cells and enhancing the lymphocytopenic grade. Deep lymphocytopenia is an officially recognized form of cancer therapy [27]. The low level of permissible clinical lymphocytopenia $\left(0.5 \times 10^{9} / \mathrm{L}\right)$ together with the success of conventional cytotoxic treatment is hardly compatible with stimulation of anticancer immunity; the safety of the procedure is simply ignored.

Morphogenic migratory cells include hematopoietic stem cells (HSCs), CD133+ angiogenic stem cells, recent thymus emigrants (RTEs) including terminal deoxynucleotidyl transferase-positive $(\mathrm{TdT}+)$ prelymphocytes, CD31+ angiogenic T-lymphocytes, and certain other "regulatory" cells [17] [28] [29]. As most such cells are more radiosensitive than mature cells, high doses of radiation or cytotoxic anticancer drugs may weaken stimulation by such cells of tumor growth. At the lowest doses ( $1-1.5 \mathrm{~Gy}$ ) of TBI or sTBI, most sub-lethally injured normal cells may successfully compete with a relatively small pool of malignant targets, encouraging migratory feeding cells to repair/regenerate areas other than tumor tissues [30]. Such competition between tissues may delay cancer progression even in the absence of any quantitative changes in the principal subpopulations of blood cells, which are typically not evident at whole-of-life irradiation doses $\leq 0.003 \mathrm{~Gy} /$ day [9]. If malignant progression depends on cellular proliferative potency more than on anticipated anticancer immunity, interesting questions arise: How long will stimulation of anticancer immunity dominate the explanation of how hormetic phenomena influence the LS? How long will the radiation hormesis model conflict with the non-threshold hypothesis of radiobiology? To answer these questions, we need to know how hormesis varies with the tissue-renewal status of irradiated normal subjects. If the effects of radiation hormesis in terms of the LS are accompanied by loss of somatic viability, hormesis cannot be interpreted as stimulating immunity and vice versa. The appropriate radiation dose during such a protracted period must align with the "tolerance dose" concept [31]. Such a dose, which spares all of the principal blood cell parameters during chronic irradiation [9], was used in this study. The purpose of this retrospective work was to evaluate and compare the beneficial and negative influences of whole-of-life total-body gamma irradiation on the health of dogs in terms of LS, development of malignancy, instantaneous death hazard, development of principal clinical symptoms, and pathological status, by the regenerative capacities of various tissue types.

\section{Methods}

Animals. All of the data were derived in collaboration with Professor G. Woloschak, Northwestern University (Chicago, IL, USA). The Woloschak Laboratory 
hosts several radiobiology archives that contain data and tissues from radiobiological megastudies performed in the second half of the $20^{\text {th }}$ century, which were originally described by Carnes and Fritz (1993). Data acquired by the Argonne National Laboratory (Lemont, IL, USA) were extracted from the " $\gamma$-Beagle Dog Tissue Archive". We examined data stored as: "Life span: Whole Life Gamma Irradiation, External Co-60 gamma-ray exposure, continued until death on 13-month-old dogs of both sexes"

(http://janus.northwestern.edu/dog_tissues/introduction.php). We analyzed the sections entitled "Clinical observations" and "Pathology observations," which contained data on 90 dogs of both sexes that had been originally randomized and irradiated with cobalt 60 gamma rays at $0.003 \mathrm{~Gy} /$ day for $22 \mathrm{~h}$ per day, 7 days a week, commencing at day 400 after birth and continuing until death. We also reviewed data on a control group of 169 animals (stored under: "Various Groups from Stock, Breeders and so forth; group: 100. Colony control”).

Subgroups. To evaluate hyperproliferative processes, both the control and irradiated groups were divided into two subgroups: with benign tumors or tumors of unknown nature clinically recorded during life (W), and without such tumors (WO). Solid malignancies and malignant hemoblastoses were verified by autopsy. Survival curves were generated for each of the four subgroups. Survival at time 0 was set to 1.0. The curves were convex over much of the slow-decay phase, exhibiting two linear regions (biphasic pattern) on semilogarithmic plots. The two linear regions were characterized by initially slow death rates followed by later sharp rises. Both parts were separately fitted to exponential functions using the simplest possible equation:

$$
S=\mathrm{e}^{-k t}
$$

where $S$ was survival in relative units, $t$ was the elapsed time in years, and $k$ was the hazard rate (instantaneous death rate per year) [32].

In addition to constructing survival curves based on hazard rates, survival was also investigated using the alternative subject-years method, whereby survival is presented as the instantaneous product $(\mathrm{N} \times \mathrm{T})$ of the surviving members of a population $(\mathrm{N})$ by the number of lived years $(\mathrm{T})$ at a current time and age [33]. Dog-time parameters $(\mathrm{N} \times \mathrm{T})$ are shown on the y axes and LS (or ages) is shown on the $\mathrm{x}$ axes. Thus, the subject-years method explored changes in exposure status. Two such dog-year $(\mathrm{N} \times \mathrm{T})$ curves (for control and irradiated animals) were created for each of the two groups ( $\mathrm{W}$ and WO). The $\mathrm{N} \times \mathrm{T}$ values were used to calculate two ranges of differences $\Delta(\Delta \mathrm{W}$ and $\Delta \mathrm{WO})$; thus $\Delta=[(\mathrm{N} \times \mathrm{T})$ irradiated $-(\mathrm{N} \times \mathrm{T})$ control] for each age period commencing at $0.5,1.0,1.5 \ldots$ to $15.0,15.5$, and 16.0 years of age. $\Delta$ values $>1.0$ revealed the presence of a hormestic effect, whereas $\Delta$ values $<1.0$ indicated loss of dog-years caused by irradiation. Comparisons of positive $(>1.0)$ and negative $(<1.0) \Delta$ values on the age scale yielded information on the prevalence of radiation hormesis or radiation injury during whole-life exposure to radiation of two of the subgroups (W or WO). "Graphical Analysis-Vernier version 03.01" software was used to integrate positive or negative deviations of $\mathrm{N} \times \mathrm{T}$ values by age. Microsoft Excel was used to 
derive nonlinear approximating curves (e.g., exponential, polynomial), to automatically calculate maximal correlation indices (coefficients of determination; $\mathrm{R}^{2}$ values) and to assess the goodness-of-fit of functions to data ( $\mathrm{R} \pm$ standard error $\mathrm{SE}_{\mathrm{R}}$ and probability values $\mathrm{p}$ ). The regression $t$-test was used to confirm the $\mathrm{R}$ values, with the aid of the $p$ values [34]:

$$
t=\sqrt{\left[R^{2}(n-2) /\left(1-R^{2}\right)\right]}
$$

Terms. Each of the four subgroups was characterized using certain principal parameters (average LS, malignant solid tumor percentage, and percentages of malignant hemoblastoses and anemias evident clinically during the LS and upon final pathology). The percentages of additional abnormalities were also recorded. Fisher's exact test was used to explore statistical significance. Averages ( $M$ values) and standard error (SEs) were compared using the t-criterion, if necessary.

\section{Results}

\section{1) Overview}

The LS of the overall control (11.2 \pm 0.3 years) and overall irradiated (11.7 \pm 0.25 years) groups were identical $(\mathrm{p}=0.19)$. The average principal parameters of various subgroups are shown in Table 1 . The proportions of both malignant hemoblastoses and anemias in the control WO and $\mathrm{W}$ subgroups were identical (11.5\% and $13.6 \%$, respectively), but the longer LS (11.8 years) of control W dogs was associated with a higher percentage $(60 \%)$ of solid malignancies (carcinomas, adenocarcinomas) (Table 1) together with more inflammation and tissue atrophy (Table 2). Radiation selectively extended the LS of subgroup WO (from 10.7 to 11.8 months), rendering the initial (control) difference between the two subgroups insignificant. Our preliminary data [21] showed a trend of LS towards improvement at a dose of $0.003 \mathrm{~Gy} /$ day but we did not discuss it till the present study. This appeared to be attributable to complete elimination by radiation of all of the cases of initial hemopoietic pathology (hemoblastoses and anemias), from $11.5 \%$ (control value) to $0 \%$ (Table 1 ). The percentage of solid malignancies

Table 1. The LS, proportions of solid malignancies, and pathologies of the hematopoietic system of control and exposed dogs with (W) or without (WO) any clinical sign of abnormal tissue hyperproliferation (benign or of unknown nature) during life.

\begin{tabular}{|c|c|c|c|c|c|c|}
\hline \multirow[b]{2}{*}{ Items } & \multicolumn{2}{|c|}{0 Gy/day } & \multicolumn{2}{|c|}{0.003 Gy/day } & \multicolumn{2}{|c|}{ Effect of exposure in identical subgroups $\dagger$} \\
\hline & $\begin{array}{c}W O \\
n=96\end{array}$ & $\begin{array}{c}W \\
n=73\end{array}$ & $\begin{array}{c}W O \\
n=31\end{array}$ & $\begin{array}{c}W \\
n=59\end{array}$ & WO & $W$ \\
\hline $\mathrm{LS}$, years $\mathrm{M} \pm \mathrm{SE}$, & ${ }^{\star} 10.7 \pm 0.43$ & ${ }^{\star} 11.8 \pm 0.34$ & $11.8 \pm 0.46$ & $11.5 \pm 0.28$ & $+1.1 \pm 0.63$ & $-0.3 \pm 0.44$ \\
\hline ISolid malignancies, \% & $* * 39.5 \underline{\imath}$ & $* * 60 \uparrow$ & 45 & 58 & +5.5 & -2 \\
\hline [!Hemoblastoses & 9.4 & 6.8 & 0 & 6.8 & $-9,4$ & 0 \\
\hline and anemias, $\%$ & 2.1 & 6.8 & 0 & 0 & $-2,1$ & -6.8 \\
\hline$\Sigma$ & 11.5 & 13.6 & 0 & 6,8 & $*-11.5 \uparrow$ & -6.8 \\
\hline
\end{tabular}

${ }^{*} \mathrm{p}$ values are given only if the differences are significant: ${ }^{*} 0.01<p \leq 0.05,{ }^{*} 0.001<p \leq 0.01,{ }^{* * *} p \leq 0.001 ; \dagger:$ (irradiation minus control). $\underline{\uparrow}$ : by Fisher's exact test; !!: verified by autopsy. 
Table 2. Proportions (\%) of additional physiological abnormalities recorded in the control WO and W subgroups during the LS.

\begin{tabular}{|c|c|c|c|c|c|}
\hline \multirow[b]{2}{*}{ Items } & \multicolumn{2}{|c|}{ Subgroups } & \multirow[b]{2}{*}{ Items } & \multicolumn{2}{|c|}{ Subgroups } \\
\hline & $\begin{array}{c}W O \\
n=96\end{array}$ & $\begin{array}{c}W \\
n=73\end{array}$ & & $\begin{array}{c}W O \\
n=96\end{array}$ & $\begin{array}{c}W \\
n=73\end{array}$ \\
\hline Inflammation, $\%$ & $* * * 57$ & $* * * 75$ & Extensive body weight loss \% & 15 & 21 \\
\hline Atrophy, \% & $* * * 9,3$ & $* * * 19$ & Diarrhea, \% & 52 & 51 \\
\hline Obesity \% & 39.5 & 42 & Vomiting, \% & 50 & 41 \\
\hline $\begin{array}{l}\text { Reduction in } \\
\text { appetite, \% }\end{array}$ & 19 & 23 & Metaplasia, \% & 1 & 0 \\
\hline
\end{tabular}

$\mathrm{p}$ values are given only if the differences were significant: ${ }^{*} 0.01<p \leq 0.05,{ }^{*} 0.001<p \leq 0.01,{ }^{* * *} p \leq 0.001$.

in the irradiated WO subgroup was slightly elevated, neutralizing the initial difference between $\mathrm{WO}$ and $\mathrm{W}$ animals and confirming the unidirectional relationship between disease incidence and LS.

The observed increase in the proportion of solid tumors in irradiated WO dogs (from $39.5 \%$ to $45 \%$; Table 1 ) may be attributable to prolongation of life, by analogy with the interdependence of these parameters evident in the control data of Table 1. The longer the LS in control $\mathrm{W}$ dogs with clinical signs of hyperproliferation (11.8 years), the more solid malignancies (60\%) were found after death.

2) Survival analysis as revealed by semi-logarithmic plotting

Semi-logarithmic survival curves are compared in Figure 1(a) and Figure 1 (b).

The instantaneous hazard rates ( $k$ values/year) for the exponential functions (Equation (1) are shown in Table 3

Figure 1(a) and Table 3 show that, in the control WO subgroup with a shorter LS, the hazard rate $k_{1}$ during the first part of life was 2.6-fold greater than that of subgroup W (0.072/year vs. 0.028 /year). The principal reason may be that hematopoietic disorders were more prevalent in control WO animals (Table 1).

In the WO subgroup, irradiation was associated with obvious declines in the hazard rates $k_{1}$ (2.9-fold) and $k_{2}$ (1.5-fold). In the W subgroup, both $k_{1}$ and $k_{2}$ were also reduced, but only slightly (2.06-fold and 1.39-fold respectively) (Figure 1 and Table 3). Thus, the most prominent hormetic decline was in the $k_{1}$ of the WO subgroup.

However, the zones between the two exponential regions (the "middle-age" zones 10 - 13 years) of each curve of Figure 1 cannot be evaluated or quantitatively compared in this manner. A precise analysis follows.

3) Survival in terms of dog-years.

The plots are shown in Figure 2(a) and Figure 2(b). The approximating lines prove that hormetic phenomenon prevails also in the problem "middle-age" zone (10 - 13 years) of WO dogs. A comparison of the integrals of Figure 2(a) and Figure 2(b) confirms that selective radiosensitivity increased survival (mostly in the WO subgroup with basal hematopoietic weaknesses). The positiv- 
ities of the dog-years of the irradiated WO subgroup increased by about 10 years. The overall survival increase was $16 \%$ (integrals from 65.2 to 75.0 ; Figure $2(a))$ in the entire WO dog population with potentially abnormal hemopoiesis No radiogenic improvement was evident in $\mathrm{W}$ subgroup dogs (the integrals
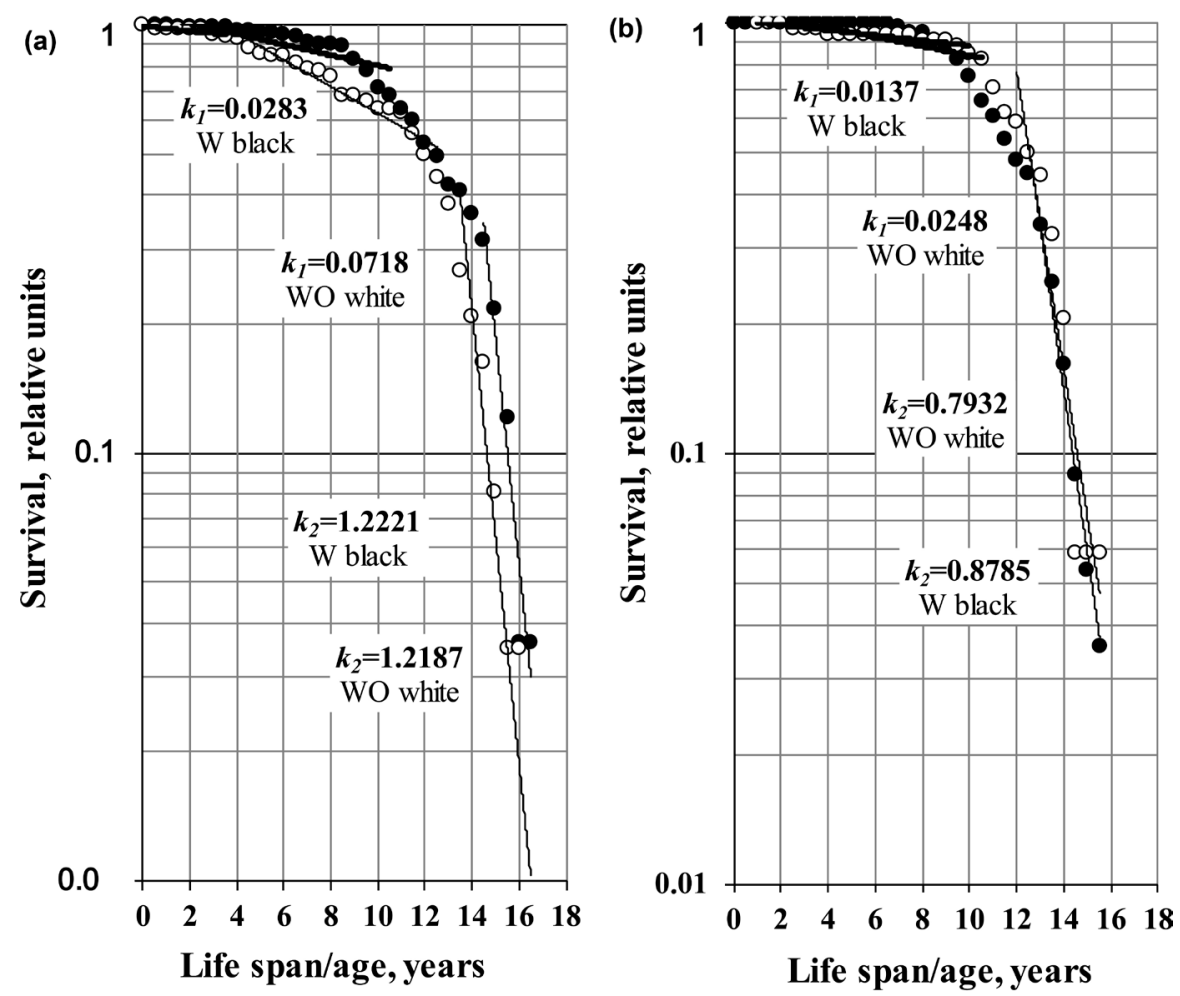

Figure 1. Survival of control (a) and irradiated dogs (b) of subgroup W with visible or palpable neoplasms (black circles) and those of subgroup WO without such neoplasms (white circles). $k_{1}$ and $k_{2}$ are the hazard rates of the first (slow) and second (rapid) exponential regression lines of subgroups $\mathrm{W}$ and $\mathrm{WO}$, respectively.

Table 3. Hazard rates ( $\mathrm{k}$ values, year ${ }^{-1}$ ) for death during the initial (slow) phase 1 and the final (rapid) phase 2 of the biphasic survival curves for the $\mathrm{W}$ and $\mathrm{WO}$ subgroups.

\begin{tabular}{|c|c|c|c|c|c|c|c|}
\hline \multicolumn{2}{|c|}{ Dose rate, Gy/day } & \multicolumn{2}{|c|}{$0^{\mathrm{a}}$} & \multicolumn{2}{|c|}{$0.003^{\mathrm{b}}$} & \multicolumn{2}{|c|}{$\begin{array}{l}\text { Reduction in hazard rate } k \text { in } \\
\text { irradiated dogs ( } n \text {-fold values for } \\
\text { identical exponential numbers) }\end{array}$} \\
\hline & $\begin{array}{l}\text { roup and } \\
\text { nt numbers }\end{array}$ & $\exp 1$ & $\exp 2$ & $\exp 1$ & $\exp 2$ & $\exp 1$ & $\exp 2$ \\
\hline \multirow[b]{2}{*}{$W O$} & $k_{\mathrm{wO}}$ & 0.072 & 1.22 & 0.025 & 0.79 & \multirow[b]{2}{*}{2.9} & \multirow[b]{2}{*}{1.5} \\
\hline & $\begin{array}{c}\mathrm{R} \pm \mathrm{SE}_{\mathrm{R}} \\
\mathrm{n}\end{array}$ & $\begin{array}{c}0.96^{* * *} \pm 0.018 \\
19\end{array}$ & $\begin{array}{c}0.95^{\star * \star} \pm 0.04 \\
6\end{array}$ & $\begin{array}{c}0.73^{* * *} \pm 0.16 \\
19\end{array}$ & $\begin{array}{c}0.95^{\star * *} \pm 0.035 \\
8\end{array}$ & & \\
\hline \multirow[b]{2}{*}{$W$} & $k_{\mathrm{W}}$ & 0.028 & 1.22 & 0.014 & 0.88 & \multirow[b]{2}{*}{2.06} & \multirow[b]{2}{*}{1,39} \\
\hline & $\begin{array}{c}\mathrm{R} \pm \mathrm{SE}_{\mathrm{R}} \\
\mathrm{n}\end{array}$ & $\begin{array}{c}0.84^{\star \star \star} \pm 0.061 \\
22\end{array}$ & $\begin{array}{c}0.96^{* * *} \pm 0.032 \\
5\end{array}$ & $\begin{array}{c}0.81^{\star * \star} \pm 0.13 \\
22\end{array}$ & $\begin{array}{c}0.99^{* * *} \pm 0.005 \\
7\end{array}$ & & \\
\hline \multicolumn{2}{|c|}{ Ratio $k_{W O} / k_{W}(\mathrm{n}$-fold $)$} & 2.6 & 1.0 & 1.8 & 0.9 & \multicolumn{2}{|c|}{ Ratio $k_{W O} / k_{W}(\mathrm{n}$-fold $)$} \\
\hline
\end{tabular}

${ }^{a}$ see Figure 1(a); ${ }^{b}$ see Figure 1(b); ${ }^{\mathrm{R}} \pm \mathrm{SE}_{\mathrm{R}}$ was the factor used when deriving correlations exhibiting approximately exponential lines given by the equation $S=\mathrm{e}^{-k t}$, where $S$ was survival and $t$ elapsed time, in years. $p$ values are only shown if they are significant: ${ }^{\star} 0.01<p \leq 0.05,{ }^{*} 0.00<p \leq 0.01,{ }^{* * *} p \leq 0.001$. The correlation coefficients ( $\mathrm{R}$ values) for the eight regression lines were automatically calculated by Microsoft Excel and also are shown in Table. 

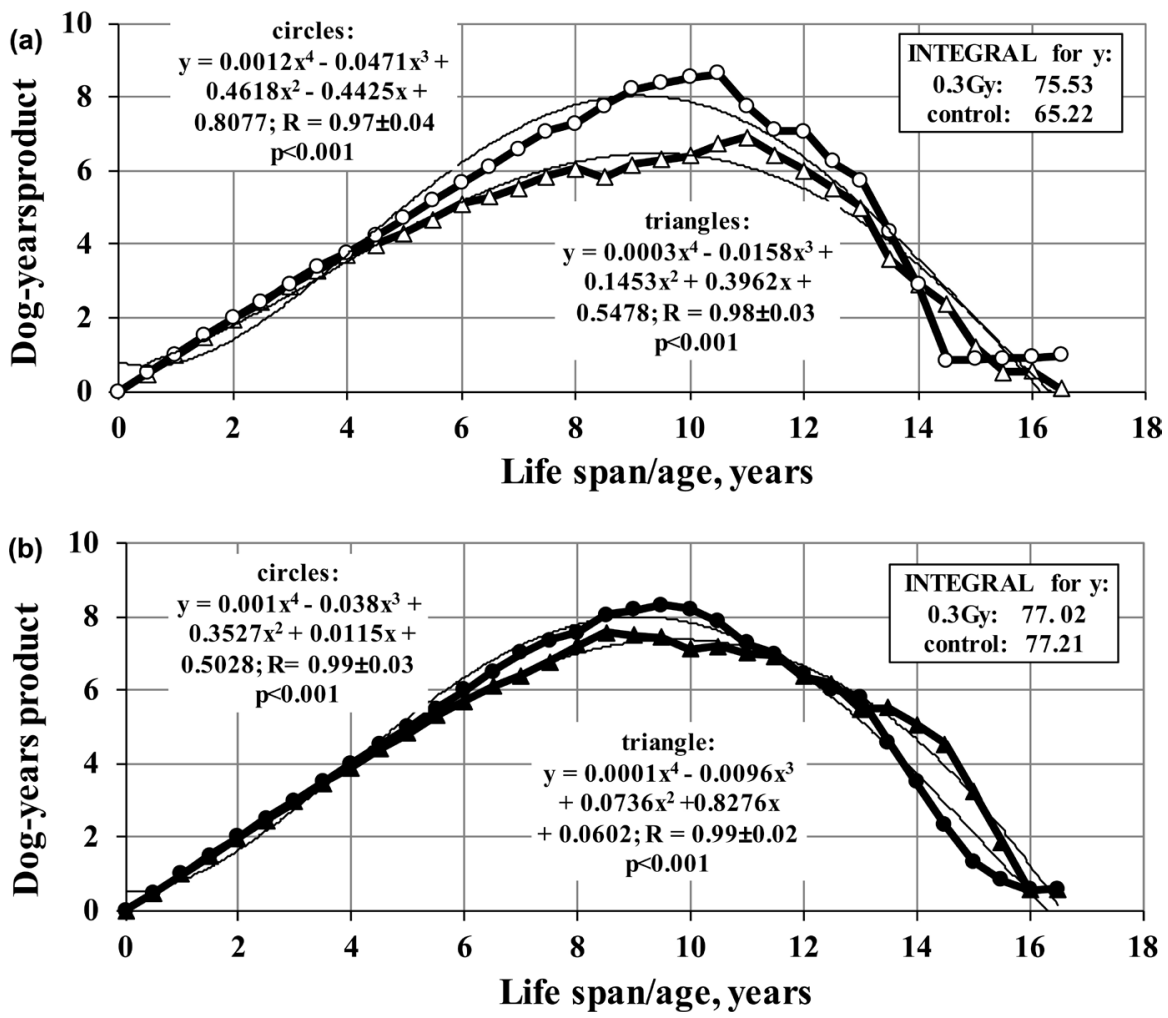

Figure 2. Dog-years of survival in control (triangles) and irradiated (circles) dogs of the WO subgroups (without visible or palpable neoplasms; (a) white markers) and the W subgroups (with visible or palpable neoplasms; (b) black markers) The equations for the four thin regression lines with the correlation coefficients shown (the $\mathrm{R}$ values) were automatically calculated by Microsoft Excel and are shown inside the plots. The integrals (dog-year products) were automatically calculated by Graphical Analysis-Vernier software, version 03.01, and are shown in boxes.

ranged from 77.2 to 77.0; Figure 2(b)).

Figure 3 shows age/dose-dependent variation in dog-year products in detail (as differences [ $\Delta$ values] between irradiated and control animals in each of the WO and W subgroups).

The black area (subgroup W) in Figure 3 shows that the slight initial benefit (+3.57 integral dog-years) and the late negative component (-3.76 integral dog-years) were approximately identical. However, in the WO subgroup (the white area of Figure 3), early hormesis (+10.5 integral dog-years) prevailed over the minimal late loss of viability ( -0.19 integral dog-years). Thus, radiation hormesis is not a permanent, but rather, is a passing phenomenon that is most prevalent in WO animals with a basally reduced LS and fewer solid malignancies (Table 1). Hormesis was principally in frail animals in whom irradiation triggered extensive atrophy and body weight loss (Table 4), accompanied by almost complete elimination of hemopoietic abnormalities but a slight increase in the number of solid malignancies (Table 1). Common features of irradiated $\mathrm{WO}$ and $\mathrm{W}$ animals included prominent cell type conversion in the BM (metaplasia), reduced inflammation, and deterioration of digestive system function (Table 4). 


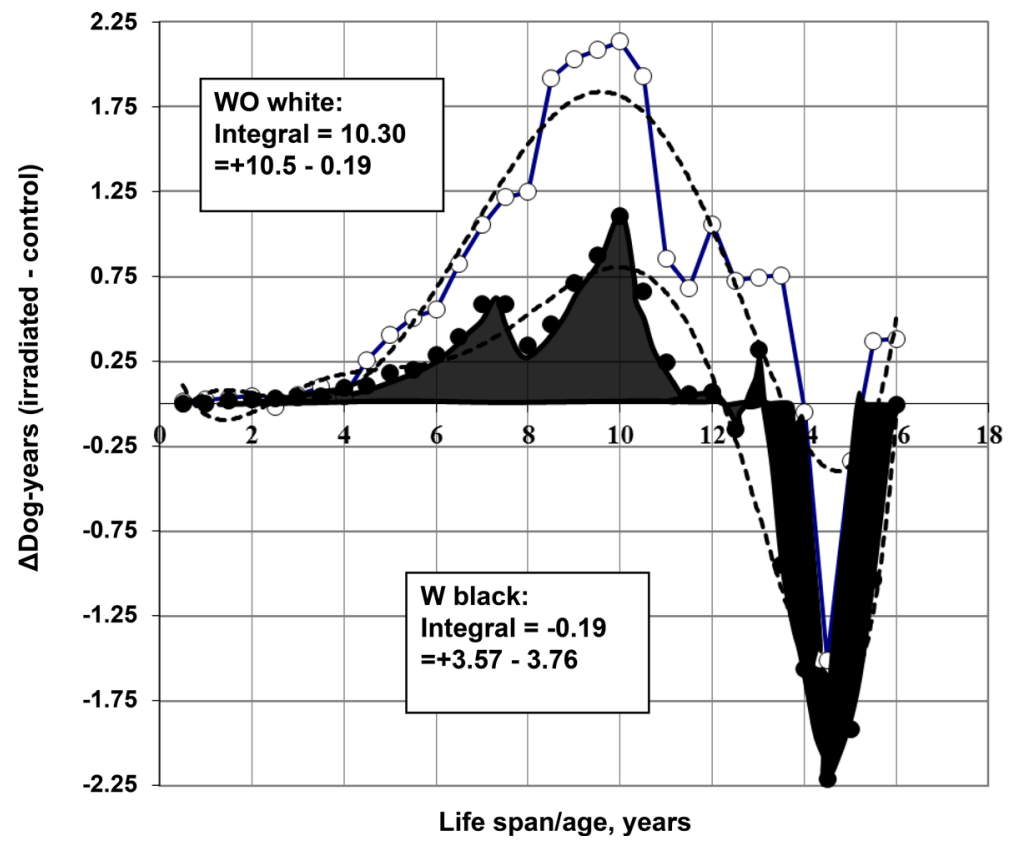

Figure 3. Dog-year product differences $(\Delta s)$ between irradiated and control animals in the WO and W subgroups. The differences in dog-year integrals between irradiated and control dogs in subgroup WO (white) and W (black) were automatically calculated by Graphical Analysis-Vernier software, version 03.01, and are shown in boxes. Each curve consists of a positive (radiation hormesis) and a negative (radiation harm) component. Dashed line calculated by Microsoft Excel for WO: $y=0.0002 x^{5}-0.0073 x^{4}+0.0863 x^{3}-$ $0.3773 x^{2}+0.6313 x-0.2725 ; R \pm S E_{R}=0.91 \pm 0.08 ; p<0.001 ;$ Dashed line calculated by Microsoft Excel for $W: y=4 E-05 x^{6}-0.0016 x^{5}-0.0258 x^{4}+0.1958 x^{3}-0.7257 x^{2}+$ $1.1335 x+0.5162 ; R \pm S E_{R}=0.94 \pm 0.06 ; p<0.001$.

Table 4. Abnormalities recorded during the LS in organs and physiological systems of irradiated dogs of subgroups WO and W compared to controls.

\begin{tabular}{|c|c|c|c|c|}
\hline \multirow{2}{*}{ Items } & \multicolumn{2}{|c|}{$\begin{array}{l}\text { Irradiated } \\
\text { subgroup, \% }\end{array}$} & \multicolumn{2}{|c|}{$\begin{array}{l}\text { Ratio } 0.003 / \text { control for identical subgroups } \\
\qquad(\mathrm{n} \text {-fold and } \mathrm{p})\end{array}$} \\
\hline & WO & $W$ & $W O$ & $W$ \\
\hline \multirow{2}{*}{ Metaplasia } & \multirow{2}{*}{19} & \multirow{2}{*}{17} & $* * 19 \underline{\underline{\imath}}$ & $*^{* *} \gg 19 \underline{\imath}$ \\
\hline & & & 0.0019 & 0.0012 \\
\hline \multirow[t]{2}{*}{ Inflammation } & \multirow[t]{2}{*}{26} & \multirow[t]{2}{*}{32} & ${ }^{*} 0.46 \underline{\underline{\imath}}$ & ${ }^{* * *} 0.43 \underline{\underline{\imath}}$ \\
\hline & & & 0.0015 & $<0.001$ \\
\hline \multirow{2}{*}{ Diarrhea } & \multirow{2}{*}{77} & \multirow{2}{*}{76} & ${ }^{*} 1.48 \uparrow$ & ${ }^{* * *} 1.49 \uparrow$ \\
\hline & & & $\mathrm{p}=0.007$ & $<0.001$ \\
\hline \multirow{2}{*}{ Vomiting } & \multirow{2}{*}{94} & \multirow{2}{*}{93} & ${ }^{* * *} 1.88 \uparrow$ & $\star * * 2.27 \underline{1}$ \\
\hline & & & $<0.001$ & $<0.001$ \\
\hline \multirow{2}{*}{ Reduced appetite } & \multirow{2}{*}{$23^{*}$} & \multirow{2}{*}{$42^{*}$} & 1.21 & ${ }^{\star} 1.83 \underline{\imath}$ \\
\hline & & & ns & 0.013 \\
\hline \multirow{2}{*}{ Obesity \% } & \multirow{2}{*}{29} & \multirow{2}{*}{20} & 0.74 & ${ }^{\star *} 0.48 \rrbracket$ \\
\hline & & & ns & 0.004 \\
\hline \multirow{2}{*}{ Atrophy, \% } & \multirow{2}{*}{61} & \multirow{2}{*}{51} & $* * * 6.6 \underline{1}$ & $* * * 2.7 \underline{1}$ \\
\hline & & & $<0.001$ & $<0.001$ \\
\hline \multirow{2}{*}{ Extensive body weight loss \% } & \multirow{2}{*}{32} & \multirow{2}{*}{19} & ${ }^{*} .13 \uparrow$ & 0.9 \\
\hline & & & 0.02 & $\mathrm{~ns}$ \\
\hline
\end{tabular}

$p$ values are shown only if they are significant: ${ }^{\star} 0.01<p \leq 0.05,{ }^{*} 0.001<p \leq 0.01,{ }^{* * *} p \leq 0.001 ; \uparrow: p$ by Fisher's exact test. ns. not significant. 


\section{Discussion}

The speed and extent of regeneration/reparation in tissues dosed with 0.003 Gy/day preserved the LS in general populations of Beagle dogs [9]. We confirmed this conclusion in this study in which we focused on multiorgan injures developing after irradiation [35]. WO subgroups were assumed to include animals exhibiting stronger anti-cancer immunity than $\mathrm{W}$ subgroups. However, in practice, the control WO subgroup included weaker dogs with a shorter LS than W subgroup animals (Table 1). Moreover, the greater extents of body weight loss and tissue atrophy in the irradiated WO subgroup (Table 4) defied initial expectations. By contrast, the control W subgroup had a longer LS despite the presence of more solid tumors (Table 1). The greater extent of inflammation in this subgroup (Table 2) combined with the minimal loss of body weight upon irradiation (Table 4) correlated with higher cancer risks for particular organs including the liver, pancreas, and gastrointestinal tract [36] [37]. Tissue atrophy, body weight loss, and myelo-immunosuppression are typical "side-effects" of conventional cytotoxic radiochemotherapy, inseparable from the benefits afforded by anti-malignancy treatments [18] [23] [24] [27] [30]. Thus, the greaterbody weight loss of, and the higher-level atrophy in the irradiated WO subgroup (Table 4) may indicate that the extent of tissue injury was sufficient (optimal) for selective induction of hormesis. If this is correct, the radiation-induced injures to subgroup $\mathrm{W}$ may be suboptimal because control dogs were healthier [20] [21] and lived longer despite developing more solid malignancies (Table 1). Such a conclusion is in accordance with the data of Figure 3. The right border of the cumulative dose inducing the hormetic phenomenon in WO animals was larger (14.8 Gy at 13.5 years) than that of W animals (13.1 Gy at 12 years).

Thus, the different effects of identical doses of radiation given to two subgroups of a single breed of dogs indicate that factors such as basal regenerative status influences radiation hormesis. The depth of injuries to normal tissues may differ in animals varying by health status, such as dogs of the WO and W subgroups. Health, $\mathrm{n}$ turn, is conditioned by proliferative myelopoiesis, and as such, the effects of a feeding cell numbers by their on the Hayflick's limit [38]. If this is the case, the data indicate that weaker (WO) animals are less able to produce morphogenic cells. Limited numbers of such cells trigger re-orientation them from privileged (quasi-embryonic) malignant growth toward urgent repair/ regeneration of the many injured somatic cells. Therefore, malignant proliferation is reduced, as evidenced by the reduced numbers of hemoblastoses in WO animals (Table 1), effectively preserving longevity.

In $\mathrm{W}$ animals, the morphogenic hemopoietic resource appeared to be greater, and thus adequate to serve the continuing proliferative needs of both malignant growth and regeneration of multiple radiogenic injures to normal tissues, but without development of competition between these two processes triggered by exhaustion of the morphogenic potential, as was evident in WO animals. The hormesis evident in the WO subgroup (Figure 3) co-existed with a slight increase in the proportion of solid cancers (Table 1). This is incompatible with the 
notion [39] [40] [41] that radiation stimulates anticancer immunity. The slight selective stimulation of solid carcinogenesis in WO animals, compared to W animals, may reflect a relative enhancement of proliferative activities in irradiated tissues and organs. Such switching of morphogenesis develops in cancer survivors after conventional cytotoxic treatment. All remain at an increased risk (14\%) of developing new ("second") malignancies compared to the general population [42]. Considering the absence of any hemopoietic pathology in the irradiated WO subgroup, recommitment of circulating feeding cells from contributing to potential hemoblastoses to repair of the many injured normal cells may explain the slight increase in the development of new solid malignancies, and also, the observed LS extension. Diversion of feeding cells from tumor development to repair/regeneration of many sublethally injured normal cells, including hemopoietic progenitors, was evident at low radiation doses inadequate to trigger myelosuppression [9]. This may partly explain why anemia was not noted in WO animals (Table 1).

It is remarkable that the hormetically mediated life extension in the weaker WO subgroup did not exceed the LS typical of the healthier W subgroup (Table 1 ), indicating again that no form of pure stimulation occurred. Moreover, hormesis declines with age. A natural (and abrupt) defect in the morphogenic potency of the hemopoietic system develops in dogs at about 10 years of age (Figures 1-3) [21]. At this time, thymus function ceases in dog breeds [43]. This dramatic decline in hormesis at 10 years (Figure 3 ) indicates that the process is dependent on morphogenic cells that are of lymphocytopoietic origin. There is no evidence on the direct hormetic effects of low-dose gamma radiation (by daily exposure of the mice to $0,0.002,0.01,0.05$, and 0.25 Gy for 30 days) on tissue stem cells with non-hemopoietic histotype [44].

Some advanced cancer patients given half-body irradiation at cumulative doses of about $1 \mathrm{~Gy}$ enjoyed benefits, depending on the depth of tissue injury; these patients exhibited induction of lymphocytopenia [23] [24]. The life expectancies of healthy individuals with higher proportions of circulating lymphocytes were significantly greater than those of others [45] [46]. Thus, general molecular or cellular mechanisms that ignore the specificities of cellular phenotypes and/or systemic collaborations within organisms cannot explain the importance of hormesis, as revealed in this study.

Our data unite various hormetic phenomena including "sTBI/TBI for cancer therapy" [3] [22] [23] [24] [39], "overcompensation stimulation following initial toxicity" [4] "protection against lung cancer induced by low-dose irradiation," [40] [41] [47] and "direct immune stimulation and adaptation" in populations living in areas with high natural levels of background radiation $(\approx 0.01 \mathrm{~Gy} /$ year $)$. Such residence was not accompanied by stable reductions in the numbers of circulating blood cells [4] [5] [7] [8]. All of the phenomena mentioned can be simply explained by: direct declines in circulating subpopulations of cells with morphogenic/feeding functions, and/or diversion of such cells from malignant tissue formation to repair/regeneration of many sublethally injured normal cells. 
This viewpoint does not recognize a general healing property of radiation, but rather, the partial substitution of one pathology (e.g., malignancy) by others (somatic diseases) that are less life threatening [9] [20].

\section{Summary}

The dependence of radiation hormesis on tissue regenerative status disproves the notion that hormesis is attributable to stimulation of antineoplastic immunity. Hormesis reflects the basal trophic influences of circulating cells of BM/ thymus origin on cellular renewal in both malignant and normal tissues; sublethal cellular radiation damage redirects hormetic activities to partially substitute one pathology (e.g., fatal blastoses) for others (somatic diseases) that are less lifethreatening. Recognition of a trophic axis: "lymphocytopoiesis-migrant morphogenic cells-renewal of organs and tissues" suggests that sublethal damage is actually required when hormesis occurs at low doses of radiation. This idea does not conflict with, and is actually closely related to, the concept of multiorgan injury after irradiation. In addition, it suggests that the notion of radiobiological "stimulation" is inappropriate, at least in mammals.

\section{Acknowledgements}

The authors would like to thank Professor Gayle E. Woloschak for providing access to original data of the " $\gamma$-Beagle Dog Tissue Archive."

\section{References}

[1] Luckey, T.D. (2008) The Health Effects of Low-Dose Ionizing Radiation. Journal of American Physicians and Surgeons, 13, 39-42.

http://www.jpands.org/vol13no2/luckey.pdf

[2] Vaiserman, A. (2014) Radiation Exposure. In: Rattan, S.I.S. and Le Bourg, É., Eds., Hormesis in Health and Disease, CRC Press, Taylor and Francis Group, Northwest, Washington DC, 107-152. https://doi.org/10.1201/b17042-9 https://www.crcpress.com/Hormesis-in-Health-and-Disease/R

[3] Oakley, P.A. (2015) Is Use of Radiation Hormesis the Missing Link to a Better Cancer Treatment? Journal of Cancer Therapy, 6, 601-605. https://doi.org/10.4236/jct.2015.67065

[4] Calabrese, E.J. and Baldwin, L.A. (2002) Defining Hormesis. Human \& Experimental Toxicology, 21, 91-97. https://doi.org/10.1191/0960327102ht217oa

[5] Farooque, A., Mathur, R., Verma, A., Kaul, V., Bhatt, A.N., Adhikari, J.S., Afrin, F., Singh, S. and Dwarakanath, B.S. (2011) Low-Dose Radiation Therapy of Cancer: Role of Immune Enhancement. Expert Review of Anticancer Therapy, 11, 791-802. https://doi.org/10.1586/era.10.217

[6] Doss, M. (2014) Adoption of Linear No-Threshold Model Violated Basic Scientific Principles and Was Harmful. Archives of Toxicology, 88, 849-852. http://rd.springer.com/content/pdf/10.1007\%2Fs00204-014-1208-8.pdf

[7] Calabrese, E.J. (2015) On the Origins of the Linear No-Threshold (LNT) Dogma by Means of Untruths, Artful Dodges and Blind Faith. Environmental Research, 142, 432-442. https://doi.org/10.1016/j.envres.2015.07.011

[8] Dobrzyński, L., Fornalski, K.W. and Feinendegen, L.E. (2015) Cancer Mortality 
among People Living in Areas with Various Levels of Natural Background Radiation. Dose-Response, 13, 1-10. https://doi.org/10.1177/1559325815592391

[9] Fliedner, T.M., Graessle, D.H., Meineke, V. and Feinendegen, L.E. (2012) Hemopoietic Response to Low Dose-Rates of Ionizing Radiation Shows Stem Cell Tolerance and Adaptation. Dose-Response, 10, 644-663.

[10] Orient, J.M. (2014) Fukushima and Reflections on Radiation as a Terror Weapon. Journal of American Physicians and Surgeons, 19, 48-55. http://www.jpands.org/vol19no2/orient.pdf

[11] Shoutko, A. and Shatinina, N. (1998) Chronic Cancer-Could It Be? International Journal of Integrative Medicine, 2, 36-40. http://www.iaam.nl/coherence/msaima/298-3.HTML

[12] Shoutko, A. and Yurkova, L. (2001) Indirect Control of Tumor Growth in Radiotherapy. International Journal of Integrative Medicine, 2, 36-40. http://www.iaam.nl/coherence/coherence0001.htm

[13] Shoutko, A.N., Ekimova, L.P., Vasilyeva, M.J. and Shatinina, N.N. (2002) Tissue Factors Involved in Cancer Induction. In: Peter, J., Schnider, G. and Bayer, A., Eds., High Level of Natural Radiation and Radon Areas: Radiation Dose and Health Effects, Bundesamt fur Strahlenscutz Schriften, Munich, 467-470. https://www.cabdirect.org/cabdirect/abstract/20023093831

[14] Kucia, M., Ratajczak, J. and Ratajczak, M.Z. (2005) Bone Marrow as a Source of Circulating CXCR4+ Tissue-Committed Stem Cells. Biology of the Cell, 97, 133146. https://doi.org/10.1042/BC20040069

[15] Drapeau, C. (2010) Cracking the Stem Cell Code: Demystifying the Most Dramatic Scientific Breakthrough of Our Times. Sutton Hart Press, Portland. http://www.amazon.com/Cracking-Stem-Cell-Code-Miraculous/dp/098102095X

[16] Shoutko, A., Ekimova, L., Mus, V. and Sokurenko, V. (2012) Fluctuations of CD34 + Cells Number in Blood of Cancer Patients during Final Year of Life. Medical \& Health Science Journal, 13, 7-13.

[17] Shoutko, A.N., Gerasimova, O.A., Ekimova, L.P., Zherebtsov, F.K., Mus, V.F., Granov, D.A. and Granov, A.M. (2016) Long-Term Activation of Circulating Liver-Committed Mononuclear Cells after OLT. Jacobs Journal of Regenerative Medicine, 2, Article ID: 011.

http://regenerativemedicine.jacobspublishers.com/images/Regenarative/J_J_Regene r_Med_1_3_011.pdf

[18] Su, Z., Mao Y.P., Ou, Y.P.Y., Tang, J., Lan, X.W. and Xie, F.Y. (2015) Leucopenia and Treatment Efficacy in Advanced Nasopharyngeal Carcinoma. BMC Cancer, 15, 429. https://doi.org/10.1186/s12885-015-1442-3

[19] Harding, C. (2012) Peak and Decline in Cancer Incidence, Mortality, and Prevalence. Cancer, 118, 1371-1386. https://doi.org/10.1002/cncr.26376

[20] Shoutko, A.N. and Ekimova, L.P. (2014) The Impact of Middle Age on the Viability of Patients with Nonmalignant and Malignant Diseases. Cancer Research Journal, 2, 114-120. https://doi.org/10.11648/j.crj.20140206.14

[21] Shoutko, A.N. and Ekimova, L.P. (2014a) Abnormal Tissue Proliferation and Life Span Variability in Chronically Irradiated Dogs. Radiation and Environmental Biophysics, 53, 65-72. https://doi.org/10.1007/s00411-013-0504-7

[22] Nothdurft, W. (1991) Bone Marrow. In: Scherer, E., Streffer, C., Trott, K., Eds., Radiopathology of Organs and Tissues, Springer-Verlag, Berlin, 113-169. https://doi.org/10.1007/978-3-642-83416-5_4

[23] Shoutko, A.N., Yurkova, L.E., Borodulya, K.S. and Ekimova, L.P. (2015) Lympho- 
cytopenia and Cytotoxic Therapy in Patients with Advanced Ovarian Cancer. Cancer Research Journal, 3, 47-51. https://doi.org/10.11648/j.crj.20150303.11

[24] Shoutko, A.N., Yurkova, L.E., Borodulya, K.S. and Ekimova, L.P. (2016a) Protracted Half-Body Irradiation Instead of Chemotherapy: Life Span and Lymphocytopenia in Relapsed Ovarian Cancer. International Journal of Tumor Therapy, 5, 1-7.

[25] Song, C.W., Lee, Y.J., Griffin, R.J., Park, I., Koonce, N.A., Hui, S., Kim, M.S., Dusenbery, K.E., Sperduto, P.W. and Cho, L.C. (2015) Indirect Tumor Cell Death after High-Dose Hypofractionated Irradiation: Implications for Stereotactic Body Radiation Therapy and Stereotactic Radiation Surgery. International Journal of Radiation Oncology, Biology, Physics, 93, 166-172. https://doi.org/10.1016/j.ijrobp.2015.05.016

[26] Heinzerling, J.H., Cho, J. and Choy, H. (2011) The Role of Radiotherapy in the Treatment of Metastatic Diseases. In: Lyden, D., Welch, D.R. and Psaila, B., Eds., Cancer Metastasis. Biologic Basis and Therapeutics, Cambrige University Press, New York, 612-621. https://doi.org/10.1017/cbo9780511976117.055

[27] Common Terminology Criteria for Adverse Events v3.0 (CTCAE). March 31, 2003, Publish Date: 9 August 2006, American National Standards Institute. https://ctep.cancer.gov/protocoldevelopment/.../ctcaev3.pdf

[28] Lai, Y.P., Jeng, C.J. and Chen S.C. (2011) The Roles of CD4+ T Cells in Tumor Immunity. Immunology, 2011, Article ID: 497397

[29] Shoutko, A.N., Gerasimova, O.A., Ekimova, L.P., Zherebtsov, F.K. and Granov, A.M. (2015) Features of Subpopulation Composition of Blood Lymphocytes in Recipients within the First Month after Liver Transplantation. Vestnik Transplantologii i Iskustbennich Organ, 17, 68-73.

[30] Shoutko, A.N. and Ekimova, L.P. (2014) Lymphocytopenia Can Contribute in Common Benefit of Cytotoxic Therapy of Cancer. Inter-Medical, 3, 5-13. http://www.inter-medical.ru/files/Archiv/26-27

[31] Cuttler, J.M. (2013) Commentary on Fukushima and Beneficial Effects of Low Radiation. Dose-Response, 11, 447-458.

https://doi.org/10.2203/dose-response.13-008.Cuttler

[32] Stewart, D.J., Behrens, C., Roth, J. and Wistuba, I.I. (2011) Exponential Decay NonLinear Regression Analysis of Patient Survival Curves: Preliminary Assessment in Non-Small Cell Lung Cancer. Lung Cancer, 71, 217-223. https://doi.org/10.1016/j.lungcan.2010.05.012

[33] Woodward, M. (2013) The Person-Years Method. In: Woodward, M., Ed., Epidemiology. Study Design and Data Analysis, CRC Press, Boca Raton, 183-203

[34] Gerstman, B.B. (2003) Stat Primer. Correlation, 14, 1-9.

[35] Fliedner, T.M., Dörr, H.D. and Meineke, V. (2005) Multi-Organ Involvement as a Pathogenetic Principle of the Radiation Syndromes: A Study Involving 110 Case Histories Documented. BJR Supplement, 27, 1-8. https://doi.org/10.1259/bjr/77700378

[36] Pergola, D.G. and Silvestris, F. (2013) Obesity as a Major Risk Factor for Cancer. Journal of Obesity, 2013, Article ID: 291546. https://doi.org/10.1155/2013/291546

[37] Font-Burgada, J., Sun, B. and Karin, M. (2016) Obesity and Cancer: The Oil that Feeds the Flame. Cell Metabolism, 23, 48-62. https://doi.org/10.1016/j.cmet.2015.12.015

[38] Shoutko, A.N., Gerasimova, O.A., Ekimova, L.P., Zherebtsov, F.K., Mus, V.F., Matyurin, K.S. and Granov, A.M. (2017) Lymphocyte Reproductive Activity Normalized to Numbers of Hematopoietic Stem Cells in Blood and Rate of Death in Fatal 
Diseases. Gene and Cell Therapy, 2, 7-15.

[39] Sakamoto, K. (2004) Radiobiological Bases for Cancer Therapy by Total or HalfBody Irradiation. Nonlinearity in Biology, Toxicology, and Medicine, 2, 293-316. https://doi.org/10.1080/15401420490900254

[40] Scott, B.R. (2011) Residential Radon Appears to Prevent Lung Cancer. Dose-Response, 9, 444-464. https://doi.org/10.2203/dose-response.11-027.Scott

[41] Scott, B.R. (2014) Radiation-Hormesis Phenotypes, the Related Mechanisms and Implications for Disease Prevention and Therapy. Journal of Cell Communication and Signaling, 8, 341-352. https://doi.org/10.1007/s12079-014-0250-x

[42] Shuryak, I., Hahnfeldt, P., Hlatky, L., Suchs, R.K. and Brenner, D.J. (2009) A New View of Radiationinduced Cancer: Integrating Short- and Long-Term Processes. Part II: Second Cancer Risk Estimation. Radiation and Environmental Biophysics, 48, 275-286. https://doi.org/10.1007/s00411-009-0231-2

[43] Holder, A., Mella, S., Palmer, D.B., Aspinall, R. and Catchpole, B. (2016) An AgeAssociated Decline in Thymic Output Differs in Dog Breeds According to Their Longevity. PLoS One, 11, e0165968. https://doi.org/10.1371/journal.pone.0165968

[44] Masuda, S., Hisamatsu, T., Seko, D., Urata, Y., Goto, S., Li, T.S. and Ono, Y. (2015) Time- and Dose-Dependent Effects of Total-Body Ionizing Radiation on Muscle Stem Cells. Physiological Reports, 3, Article ID: e12377. https://doi.org/10.14814/phy2.12377

[45] Van, Z.G. and Liang, Y. (2012) Concise Review: Hematopoietic Stem Cell Aging, Life Span, and Transplantation. Stem Cells Translational Medicine, 1, 651-657. https://doi.org/10.5966/sctm.2012-0033

[46] Alexander, N.I. (2016) Reference Values of Neutrophil-Lymphocyte Ratio, Platelet-Lymphocyte Ratio and mean Platelet Volume in Healthy Adults in North Central Nigeria. Journal of Blood \& Lymph, 6, 143.

[47] Sakai, K., Nomura, T. and Ina, Y. (2006) Enhancement of Bio-Rrotective Functions by Low Dose/Dose-Rate Radiation. Dose-Response, 4, 327-332. https://doi.org/10.2203/dose-response.06-115.Sakai

Scientific Research Publishing

Submit or recommend next manuscript to SCIRP and we will provide best service for you:

Accepting pre-submission inquiries through Email, Facebook, LinkedIn, Twitter, etc. A wide selection of journals (inclusive of 9 subjects, more than 200 journals)

Providing 24-hour high-quality service

User-friendly online submission system

Fair and swift peer-review system

Efficient typesetting and proofreading procedure

Display of the result of downloads and visits, as well as the number of cited articles

Maximum dissemination of your research work

Submit your manuscript at: http://papersubmission.scirp.org/

Or contact ojbiphy@scirp.org 